\title{
Novos objetos e novos desafios para a antropologia da saúde na contemporaneidade
}

\section{| ${ }^{1}$ Jorge Alberto Bernstein Iriart, ${ }^{2}$ Andrea Caprara |}

Resumo: O objetivo deste artigo é tecer uma reflexão sobre os objetos emergentes e os desafios teórico-metodológicos e éticos que se apresentam para a antropologia da saúde na contemporaneidade, abordando dois temas em particular: os desafios suscitados pelos avanços da biologia molecular, biotecnologias e medicina preditiva, e a análise da saúde e da doença no contexto de globalização. A antropologia da saúde nos parece chamada a se expandir nos próximos anos em redes temáticas ao redor desses dois grandes eixos centrais: por um lado, as novas definições da doença e da saúde associadas aos avanços das ciências da vida e a forma como o corpo humano é construído, transformado e redefinido como locus da gestão do risco e da incerteza; por outro, o contexto cada vez mais complexo, globalizado e desigual em que estamos vivendo tornam necessária uma abordagem antropológica igualmente mais global, no qual o processo saúde-doença deve ser analisado, cada vez mais dentro de um conjunto complexo de políticas econômicas, de relaçõos internacionais e de mobilidade de populaçôes, através de novas abordagens de pesquisa de natureza transdisciplinar.

> Palavras-chave: antropologia da saúde, globalização, biotecnologias.

\author{
${ }^{1}$ Instituto de Saúde Coletiva \\ da Universidade Federal da \\ Bahia. Endereço eletrônico: \\ iriart@ufba.br \\ 2 Departamento de Saúde \\ Pública da Universidade \\ Estadual do Ceará. \\ Endereço eletrônico: \\ andreacaprara1@gmail.com
}

Recebido em: 28/08/2011. Aprovado em: 09/11/2011. 
Gostaríamos de propor neste artigo uma discussão sobre os desafios que se apresentam para a antropologia da saúde no século XXI, a partir da emergência de novos objetos de estudos, em um mundo cada vez mais globalizado. Os avanços da biologia molecular, da genômica e das biotecnologias aportam modificaçôes nas definições da doença e da saúde, levando à própria reconfiguração do humano, o que suscita importantes questóes éticas. O corpo humano transforma-se progressivamente em um rascunho a ser corrigido e melhorado (LE BRETON, 2003) e metáforas da era digital passam a permear o discurso científico. Fala-se do corpo pós-orgânico e a neurociência, com os avanços na interface cérebro-máquina, promete libertar o cérebro dos limites de seu corpo (NICHOLELIS, 2011). Os avanços científicos, ao mesmo tempo em que aportam fantásticas promessas utópicas, em cenários que há não muito tempo atrás se limitavam à ficção científica, trazem também o temor do surgimento de novas desigualdades, outras formas de biopoder e do perigo do esfacelamento das fronteiras entre as diferentes formas de vida.

A antropologia tem por objeto o estudo do Homem (antropos), ou da forma como o humano é concebido em sua diversidade cultural e tem papel importante a desempenhar na análise crítica dos discursos associados aos projetos técnicocientíficos contemporâneos e nas importantes questôes éticas emergentes. É importante pensar, no entanto, e os antropólogos começam a se questionar, até que ponto os aparatos conceituais e metodológicos desenvolvidos pela antropologia estão adequados ao estudo dos novos objetos e questôes emergentes. A globalização, com a disseminação e popularização da internet, está provocando a intensificação dos fluxos de informação e produzindo formas originais de sociabilidade e de subjetivação. Epidemias globais com rápida disseminação como a Aids, a gripe aviária e a SARS colocam para a antropologia a necessidade de uma atuação também global (MASSÉ, 2010). Nesse contexto, conceitos clássicos da disciplina, como cultura, observação participante, etnografia e trabalho de campo, passam a ser questionados e alguns autores apontam a necessidade de elaborar uma nova pedagogia (RABINOW et al. 2008), de novos conceitos e formas de compreensão cultural (FISCHER, 2011).

Nossa pretensão, neste artigo, é tecer uma reflexão sobre os objetos emergentes e os desafios teórico-metodológicos e éticos que se apresentam para a antropologia 
da saúde na contemporaneidade, abordando dois temas em particular: os desafios suscitados pelos avanços da biologia molecular, biotecnologias e o desenvolvimento de uma medicina preditiva e da saúde e da doença no contexto de globalização. Para fundamentar nossa análise explicitaremos, nesta introdução, alguns dos conceitos que serão utilizados ao longo do texto, como os de contemporaneidade (AGAMBEN 2009), complexidade (MORIN, 2002) e transdisciplinaridade (ALMEIDA FILHO, 2005).

O conceito de contemporaneidade, tal como elaborado por Giorgio Agamben, faz referência à "singular relação [do homem] com o próprio tempo, que adere a este e, ao mesmo tempo, dele toma distância” (AGAMBEN 2009, p. 59). Nós podemos odiar o nosso tempo, assim como o protagonista do filme de Woody Allen em "Meia noite em Paris", mas sabemos que pertencemos a esse tempo e não podemos fugir dele (ibidem, p. 59). Neste artigo procuramos, nas sombras de nosso tempo, encontrar alguns aspectos e elementos que mais nos concernem e que possam iluminar nossas inquietações em um mundo sempre mais globalizado e interdependente (ibidem, p. 64). Diversos autores definem nossa contemporaneidade como "crise planetária" (MORIN, 2002), "decomposição do espaço público" e "amor líquido" (BAUMAN, 2004). Para a filosofia, os anos 1970 foram caracterizados pela assim chamada "crise da razão"(GARGANI, 1979; VATTIMO, 1985) em referência à "consciência" de que a racionalidade científica é muitas vezes apresentada enquanto forma "demasiado simplificada" da realidade. Entre as críticas ao pensamento científico, pela forma simplificada com a qual aborda a realidade, lembramos, entre outros, os trabalhos de Thomas Kuhn (1989) e Paul Feyerabend (2007). Os conceitos-chave na nossa contemporaneidade são, assim, aqueles de contexto, multiplicidade, integração e incerteza em um mundo sempre mais complexo.

Quanto ao conceito de transdisciplinaridade, consideramos não necessariamente a presença de pesquisadores de diferentes áreas trabalhando juntos, mas a integração de vários tipos de saberes disciplinares com a procura de significados e práticas baseados na experiência dos atores locais. Produz-se desta forma um conjunto de conhecimentos compartilhados entre diversos atores, incluindo aqueles que contribuem para o problema, aqueles que sofrem e aqueles que devem ser parte da solução, bem como os pesquisadores acadêmicos (ALMEIDA FILHO, 2005). 


\section{Desenvolvimentos recentes da antropologia da saúde}

A antropologia médica surge nos anos 50 do século passado enquanto uma subdisciplina na interface entre a antropologia e a saúde pública internacional. Inicialmente, basicamente empírica e aplicada, a antropologia da saúde experimentou, nas últimas décadas, um grande desenvolvimento quantitativo e qualitativo alcançando alto refinamento teórico. A influência da antropologia médica anglo-saxônica e da anthropologie de la maladielanthropologie de la santé francesas foram marcantes no desenvolvimento do campo, ressaltandose, no entanto, o crescimento de perspectivas regionais, a exemplo do Brasil, México e Canadá, nas Américas, ou da Itália, Espanha, Alemanha, Inglaterra e Holanda, na Europa. Para uma ampla revisão das diversas antropologias da saúde regionais citamos como referência a obra organizada por Francine Saillant e Serge Genest (2005).

No âmbito teórico-metodológico, a antropologia interpretativa, a antropologia simbólica e a fenomenologia tiveram grande influência na transformação da subdisciplina nos anos 1970, provocando sua reconfiguração enquanto estudo comparado de sistemas médicos como sistemas culturais (GOOD et al., 2010). Em meio à diversidade étnica nos países ocidentais, autores como Kleinman e Good manifestavam sua preocupação com o encontro terapêutico em contextos multiculturais. Os antropólogos procuraram compreender os mecanismos através dos quais a cultura influencia a saúde e a doença e como era construída a experiência da doença em um dado contexto social e cultural. Desenvolvese toda uma ênfase no significado, na experiência e nas formas de lidar com a enfermidade, na dimensão narrativa do encontro clínico e na corporeidade. A perspectiva interpretativa na antropologia médica teve papel importante na crítica de uma tradição empiricista, comportamental e centrada na racionalidade e no indivíduo enquanto valor, a exemplo do Health Belief Model (Modelos e crenças em saúde) (GOOD, 1994).

A partir dos anos 1980, no entanto, a antropologia médica passa a ser profundamente influenciada pelas teorias críticas e gender studies, com especial destaque para a obra de Michel Foucault. Antropólogos como Young, Singer, Lock e Sheper-Hughes buscaram construir uma antropologia médica crítica com ênfase nos determinantes sociais da doença e nas formas pelas quais os desequilíbrios nas relações de poder influenciam a saúde e a doença. O 
conceito de biopoder (FOUCAULT, 2004) é utilizado para analisar a ação do poder disciplinar sobre os corpos, na incorporação de tecnologias médicas e nos vários processos de medicalização.

A partir dos anos 1990, temas emergentes como as biotecnologias, os avanços na genética e os estudos em STS (science, technology and society) ganham relevância atraindo cada vez mais a atenção dos antropólogos que se inserem em novos campos de pesquisa (GOOD et al., 2010).

\section{Antropologia e saúde global}

O conceito de globalização ou de saúde global é cada vez mais utilizado para se referir a processos políticos, econômicos e demográficos que transcendem as fronteiras geográficas e que produzem tensões entre processos globais e identidades locais socialmente e culturalmente construídas (WHITEFORD; MANDERSON 2000). No processo de globalização, assistimos a uma perda da importância das fronteiras, que mantém seu valor geográfico, mas que perdem progressivamente seus significados enquanto limite cultural e social devido às migrações, aos intercâmbios culturais e sociais e às comunicações (LOCK, 2007). Assim, o conceito de cultura, tal como era utilizado pelos antropólogos, apresenta limitações. É quase um consenso que não é mais possível considerar a cultura de forma rígida, enquanto conjunto de valores e práticas partilhados por todos os membros de uma determinada comunidade (LOCK; NGUYEN, 2010). Para muitos antropólogos, no entanto, o conceito permanece teoricamente útil. Ele não deve ser concebido de forma estática ou totalizante (MARCUS; FISCHER, 1999) e sem levar em conta que os valores culturais são alvo de disputas e não estão igualmente distribuídos entre os grupos sociais (LOCK; NGUYEN, 2010). Um dos problemas apontados no uso do conceito de cultura na antropologia médica, sobretudo anglo-saxônica, é justamente a sua falta de politização, ao contrário do que acontece nos cultural studies.

Para Fischer (2011, p. 19), que defende a atualidade do conceito, "o desafio da análise cultural é o de desenvolver instrumentos de tradução e mediação para ajudar a tornar visíveis as diferenças e interesses, de acesso, de poder, de necessidades, de desejos e ainda de perspectiva filosófica." É fundamental para a antropologia contemporânea a busca da compreensão dos fatores culturais contextualizando-os histórica e politicamente, explorando questões centrais como as descontinuidades, 
os fluxos globais da informação, a intensidade das trocas sociais e a construção de identidades cada vez mais híbridas (LOCK, 2007).

A transição do estudo de culturas exóticas para a análise das sociedades de pertencimento levou à reflexão sobre a prática da etnografia. No contexto europeu, desenvolveu-se nos últimos anos um amplo projeto de "antropologia em casa" (anthropology at home), principalmente no campo da saúde (VAN DONGEN; FAINZANG, 1998). Com o interesse crescente dos antropólogos por novos objetos, como o estudo social e cultural da ciência e tecnologia e a concomitante inserção dos antropólogos em outros campos de prática, a exemplo dos laboratórios científicos (LATOUR; WOOLGAN, 1979; RABINOW, 1999), assistimos ao surgimento de uma série de conceitos utilizados na etnografia contemporânea. Marcus (1995) propõe a etnografia "multissituada" (multisited) que define como objeto de estudo os fenômenos sociais que não podem ser compreendidos, concentrando-se somente em um único contexto.

Novas formas de reprodução cultural e territorial da identidade dos grupos foram surgindo dentro da "sociedade global". Appadurai, por exemplo, criou o neologismo ethnoscape para descrever esses fenômenos transnacionais e interculturais, decorrentes de mudanças globais na sociedade (APPADURAI, 1996). Ethnoscapes são as paisagens da identidade do grupo e não estão vinculadas a territórios específicos; o sufixo "scape" significa distribuição transnacional de elementos correlacionados cuja exibição pode ser representada como paisagem (APPADURAI, 1996). Para Appadurai, os acordos transnacionais de recursos tecnológicos, financeiros, mídia e políticos podem ser vistos, respectivamente, como technoscapes, financescapes, mediascapes e ideoscapes (APPADURAI 1996, p. 33). O prefixo "etno" refere-se ao "povo" ao invés do conceito de grupo étnico.

Didier Fassin destaca como a universalização de certos valores é portadora, ao mesmo tempo, de reações de cristalização das identidades, sejam religiosas, étnicas ou artísticas (FASSIN, 2001). A abertura do espaço internacional à livre circulação de mercadorias acompanha-se sempre de maiores restriçôes impostas à circulação de pessoas, como tem sido observado em toda a Europa Ocidental, nas Américas, África e Ásia, na questão dos estrangeiros ilegais (FASSIN, 2007). Ao mesmo tempo, os efeitos da globalização podem ser percebidos através de diversas formas: o corpo, por exemplo, é cada vez mais o locus de atualização do poder moderno através da Medicina preditiva, da utilização de células-tronco 
na regeneração de tecidos diversos, da fecundação artificial, da morte cerebral,

da eutanásia voluntária, assim como dos transplantes e do comércio de órgãos (SCHEPER HUGHES, 2000). Num contexto de crescentes desigualdades globais de condições econômicas e sociais de saúde, a realização dos "Objetivos de Desenvolvimento do Milênio” estabelecidos pela comunidade internacional para combater a fome e a pobreza no mundo, melhorar o estado de saúde e reduzir as diferenças entre as populações do planeta é inexoravelmente mais distante (MARMOT, 2007).

A emergência e a rápida transmissão de novas epidemias, gripe aviária, Aids, SARS, tem aberto uma série de questôes que não podem ser abordadas apenas no plano local, através de pesquisas antropológicas sobre as percepçôes, representações sociais e práticas associadas à doença, assim como nas décadas de 1970-80. Um primeiro exemplo, é ilustrado por Parker em relação à vulnerabilidade da Aids (PARKER, 2000). A doença é hoje cada vez mais compreendida em relação a questôes de iniquidade econômica e de injustiça social. Esta análise forçou o autor a reexaminar as dinâmicas do poder, seja no âmbito das relações de gênero e da sexualidade, ou das estruturas e processos globais (PARKER, 2000, p. 40).

Um segundo exemplo aborda o caso da dengue. O reaparecimento da dengue está afetando principalmente as áreas urbanas da América Latina, Caribe, Ásia e, mais recentemente, a região do Mediterrâneo Oriental, representando um grave problema de saúde coletiva mundial (ARUNACHALAM et al., 2010; BARRETO; TEIXEIRA, 2008). Na cidade de Fortaleza, apesar do aumento das medidas de controle, a presença do vírus tem representado um problema endêmico complexo, desde 1986, com surtos epidêmicos frequentes (CAPRARA et al. 2009). A cidade cresceu explosivamente desde meados dos anos sessenta e no processo de expansão foi literalmente "engolindo" as áreas rurais ao redor, criando situações em que áreas altamente urbanizadas se mesclam com áreas com características tipicamente rurais.

Ainda existem lacunas de conhecimento para a implementação de estratégias de controle que levem em consideração as necessidades e práticas da comunidade, a ecologia do vetor, o contexto político e o desenvolvimento de novas abordagens centradas na comunidade. A abordagem antropológica, que explora as percepções da comunidade, a experiência e os significados associados à doença e ao Aedes aegypti (mosquito que transmite os quatro sorotipos do vírus causador da doença), 
pode ser insuficiente para compreender a dimensão social e cultural, se não se levam em conta outros aspectos muito mais complexos e que exploram também o universo ambiental, a ecologia e a dimensão cultural. É necessário superar a distinção entre natureza e cultura, adquirindo uma perspectiva ecoantropológica (DESCOLA, 1996). Isto significa abordar a questão da dengue através de uma perspectiva transdisciplinar, uma vez que vários aspectos se interpenetram, como a degradação ambiental em áreas urbanas, a gestão de resíduos sólidos, a gestão da água, os processos de migração e urbanização, conjuntamente com a ecologia do vetor. Para enfrentar essa doença do ponto de vista antropológico, é claro que conceitos como modelos explicativos, representação social e percepção da doença são insuficientes para descrever e interpretar o problema.

\section{A antropologia da saúde frente aos avanços da biologia molecular, da medicina preditiva e da redefinição do humano}

As novas fronteiras da Medicina confrontam a antropologia da saúde com novas questões. Não há dúvidas sobre o profundo impacto que os avanços nas ciências da vida terão sobre a sociedade e as formas de estar no mundo. Paul Rabinow (1999, p. 141), em artigo bastante influente, afirma que "a nova genética deverá remodelar a sociedade e a vida com uma força infinitamente maior que a revolução na física jamais teve, porque será implantada em todo o tecido social por práticas médicas e uma série de outros discursos". As tecnologias emergentes implicam modificaçōes na forma das pessoas se relacionarem com o corpo, com os riscos e os sentidos de controle sobre a vida, criando outros modelos de subjetividade (ORTEGA; ZORZANELLI, 2011). Elas alteram não apenas os corpos dos indivíduos, mas a forma como o corpo humano é construído enquanto categoria de pensamento do social (BRODWIN, 2000).

Os antropólogos, a partir de diferentes perspectivas e recortes empíricos, têmse debruçado sobre estes objetos emergentes, trazendo uma visão crítica sobre os discursos produzidos em torno dos novos saberes e tecnologias. A crítica ao discurso simplificador do determinismo genético é empreendida por vários autores (SFEZ, 1996; BRODWIN, 2000; LE BRETON, 2003; BIBEAU, 2010) e um ponto central na discussão é a questão da redefinição do próprio conceito de humanidade. 
Bibeau (2010) faz uma crítica radical ao que ele denomina de "genomitologia", ou o discurso reducionista construído pela bioindústria em torno da determinação genética e frequentemente reproduzido de forma acrítica pela mídia. Esse mito repousa na ideia de que a biologia molecular e o genoma funcionam como um programa informático e que a vida dos seres vivos pode ser reprogramada. As metáforas da era digital se disseminam na biologia, que se torna uma ciência da informação (LE BRETON, 2003). Nesse processo, o sujeito humano concreto se dissolve em seu programa genético, reduzindo-se a seus componentes elementares enquanto um feixe de informaçōes. Le Breton alerta para o risco do rompimento das ontologias clássicas e o consequente desaparecimento das distinções de valor entre o homem e seus instrumentos. Para Bibeau (2010), é a própria humanidade que está em perigo com o desvanecimento do sistema de valores humanistas no processo de banalização da vida e de redução da biologia à busca do gen. Para este autor, o grande discurso da geno-mitologia pode nos levar ao pós-humanismo ou ao "inumanismo", onde as fronteiras entre as diferentes formas de vida, através das transferências de genes ou correção dos genomas tornam-se borradas. No pós-humanismo, os valores centrais à filosofia moral humanista, em suas formas clássica e moderna, deixam de ser a única norma. O risco é que o discurso moral passe a ser substituído pelo discurso técnico (BRODWIN, 2000) e a definição do humano, questão debatida durante séculos pelos filósofos, seja agora respondida pelos geneticistas, bioéticos, ou pelos proprietários da bioindústria (BIBEAU, 2010).

A antropologia médica tem papel importante na construção de um novo humanismo adequado à era bio-tecnológica, através da vigilância crítica e estética frente às transformações na definição do humano (BIBEAU, 2010). Segundo Bibeau, é necessário construir um humanismo antropo-tecnológico que não tema o poder das geno-tecnologias e que leve em consideração o saber da biologia molecular, da genômica e das neurociências. Para tanto, é importante desconstruir a ideologia reducionista em torno da genética molecular quando ela faz uma leitura rasa da vida e do humano. A antropologia médica tem papel importante neste debate, aportando seu saber sobre a história da vida e da origem das doenças complexas na íntima relação entre vida e meio ambiente. Conceitos como o de "biologias locais" (LOCK; NGUYEN, 2011) são interessantes para mostrar, em oposição ao determinismo genético, como os processos biológicos 
1262 e sociais estão profundamente interligados produzindo, ao longo do tempo, diferenças biológicas. A abordagem antropológica, com seus modelos complexos e holísticos deve se contrapor aos modelos reducionistas que retiram a pessoa de seu contexto social, cultural, histórico e ambiental (BIBEAU, 2010). A antropologia traz uma visão alternativa da vida e do humano na qual estes fenômenos devem ser compreendidos a partir da interação entre o meio ambiente, a biologia, a organização social, a cultura, a história familiar e a biografia individual.

Baseado na teoria crítica, Brodwin (2000) analisa o imenso poder ideológico da biotecnologia que se apresenta como realidade necessária, dissimulando que os fatos científicos são sempre construçōes sociais. As biotecnologias são apresentadas como técnicas neutras escondendo os interesses sociais subjacentes à sua produção. É importante observar que não se trata aqui de questionar a eficácia e o grande potencial das biotecnologias para atuar sobre a saúde e a doença, mas de desvelar os valores e as dimensóes éticas e morais incorporadas à sua produção e aplicação.

A mercantilização do corpo humano, que se fragmenta em patentes em mãos de proprietários privados inserindo-se nas trocas de mercadorias na lógica do livre mercado, é uma questão preocupante que suscita uma série de questionamentos éticos. Com os avanços da genética molecular, o material genético tornou-se altamente valioso para a bioindústria. Apesar da controvérsia existente sobre o patenteamento de genes, os laboratórios têm solicitado estas patentes na América do Norte e milhares já foram concedidas. Recentemente, o Tribunal Federal de Recursos dos Estados Unidos deu ganho de causa para um laboratório que teve seu direito de patente dos genes BRCA 1 e BRCA 2, associados ao câncer de mama, questionado. O custo do exame de detecção destes genes ultrapassa os três mil dólares e, segundo os críticos do patenteamento, poderia ser bastante reduzido se não existissem as patentes $(\mathrm{O}$ ESTADO DE SÃO PAULO, 2011). A mercantilização está presente também nos bancos de esperma e óvulos que viraram uma indústria milionária em várias partes do mundo (LOCK; NGUYEN, 2010).

Vários antropólogos têm discutido, na perspectiva do biopoder (FOUCAULT, 2004), como as biotecnologias são instrumentos de medicalização e controle social. Em sua análise da utopia da saúde perfeita, Sfez (1996) já alertava para os germes totalitários subjacentes ao reforço do determinismo biológico como explicação 
das variações sociais e individuais. $\mathrm{Na}$ ideologia do gen, os comportamentos desviantes se tornam despolitizados e a medicina tem fortalecido seu papel moral de controle do desvio. O corpo humano é concebido como incompleto e imperfeito e o progresso passa então pela correção de nossa herança genética.

A perspectiva de uma medicina preditiva suscita importantes transformações na nossa concepção de saúde e de doença, além de uma série de questões éticas. A medicina pós-genômica será uma medicina personalizada, centrada sobre a capacidade de diagnosticar a doença com antecedência, prevendo probabilisticamente sua aparição e tratando-a pela terapia genética ou farmacogenômica (LOCK; NGUYEN, 2010). Como lembra Sfez, no entanto, os testes preditivos para marcadores de DNA também são formas de criar categorias sociais. No momento em que o risco genético de desenvolver uma doença é reificado como a própria doença, surge a categoria dos doentes pré-sintomáticos. Como afirma Fischer (2011, p. 66), doravante somos todos "pacientes potenciais", pois "agora reconhecemos que somos todos portadores de defeitos genéticos com predisposições variadas para a doença sob certas condições”.

Os avanços da biotecnologia implicam uma profunda modificação subjetiva na relação que os sujeitos estabelecem com o risco e com os sentidos que se atribui ao controle sobre a vida. Desta forma, a biotecnologia suscita uma redefinição do ser no mundo na qual o corpo é redefinido como locus da gestão do risco e da incerteza (MASSÉ, 2010).

Os médicos também enfrentam desafios com a reconfiguração da clínica. A doença de Hutington é um exemplo dramático. $\mathrm{O}$ teste genético pode identificar que o paciente tem o gene causador da doença. No entanto, a medicina nada pode fazer para curar este paciente ou impedir o desenvolvimento da patologia. O resultado do teste pode gerar alívio quando negativo, mas também grande sofrimento quando positivo, com repercussões psíquicas e sociais, como depressão, tentativas de suicídio, dilemas com relação às decisões reprodutivas e discriminação (GUEDES; DINIZ, 2009). Por outro lado, como lembram Guedes e Diniz (2009), há doenças genéticas, a exemplo da anemia falciforme, em que o diagnóstico precoce com acompanhamento médico e uso de medicamentos é um fator determinante para melhorar a qualidade de vida dos pacientes.

Neste debate, concordamos com Brodwin (2000) e Massé (2010), quando alertam para a necessidade de se evitar os extremos da convencional oposição 
entre tecnofilia e tecnofobia. De um lado, a visão otimista e ingênua, repleta de promessas, por vezes desmesuradas, de que as tecnologias vão melhorar a condição humana e diminuir a dor e o sofrimento. De outro, a fobia, o medo de que as biotecnologias enquanto instrumentos do biopoder reforcem as formas de dominação e destruam a autonomia dos sujeitos. A antropologia, no entanto, deve buscar compreender a ansiedade e as expectativas e promessas que a biotecnologia produz, buscando respostas contextualizadas. Massé (2010) reforça a importância dos estudos antropológicos sobre as condições e os contextos em que estas tecnologias são aplicadas, as representações dos usuários e a forma como se constroem idiomas locais de biotecnologia (BRODWIN, 2000).

É importante ressaltar que a implementação das tecnologias médicas produz também efeitos inesperados (LOCK; NGUYEN, 2010). O uso ilegal das tecnologias de imagem para selecionar o sexo dos bebês e suas consequências na exacerbação da discriminação de gênero e no desequilíbrio resultante nas taxas de natalidade por sexo, em algumas regiōes do mundo, são um exemplo contundente (LOCK; NGUYEN, 2010). O risco de que as tecnologias de reprodução emergentes, a exemplo da PGD (Preimplantation Genetic Diagnosis), sejam utilizadas para selecionar embriôes com as características desejadas e descartar outros suscita preocupaçóes com o possível surgimento de um neoeugenismo. Alguns autores receiam que o desenvolvimento das biotecnologias possa contribuir para aumentar as desigualdades sociais se os benefícios não forem acessíveis a toda a população. Como alerta Le Breton (2003), é possível imaginar cenários em que, enquanto alguns estarão manipulando os genes de seus filhos, outros estarão tentando impedir que um recém-nascido morra com diarreia. Nesse contexto, Fischer (2011, p. 67) afirma que, como analistas culturais, os antropólogos necessitam

ver (e construir) os cientistas como produtores culturais criativos e dar conta das formas pelas quais os instrumentos e as infraestruturas materiais da ciência conformam o que compreendemos, percebemos e conceituamos - e o que ao mesmo tempo é obscurecido, reprimido e retirado do cenário.

A antropologia tem papel importante na compreensão das repercussões da implementação das biotecnologias, fazendo emergir o saber local, a experiência de indivíduos e de comunidades que estão diretamente afetados pelas inovações tecnológicas, assim com as relações de poder e os dilemas éticos que lhe estão associados. 


\section{Conclusão}

Procuramos discutir aqui alguns dos desafios que se apresentam para a antropologia da saúde na contemporaneidade. A subdisciplina nos parece chamada a se expandir nos próximos anos em redes temáticas ao redor dos dois grandes eixos centrais apresentados neste trabalho: por um lado, as redefinições da doença e da saúde ligadas aos avanços da biologia molecular, da genômica, o desenvolvimento das biotecnologias e a forma como o corpo humano é construído, transformado e redefinido como locus da gestão do risco e da incerteza. Por outro, no contexto cada vez mais complexo, globalizado e desigual em que estamos vivendo, a saúde deve ser entendida em sua dimensão mais ampla, de política de saúde, abordando temáticas centrais como os determinantes sociais da saúde, os acordos transnacionais de recursos tecnológicos, financeiros, políticos, de governança e mídia, através de novas abordagens de pesquisa de natureza transdisciplinar. As questôes emergentes em um mundo globalizado tornam necessária uma abordagem antropológica igualmente mais global, no qual o processo saúdedoença deve ser analisado, cada vez mais dentro de um conjunto complexo de políticas econômicas, de relaçôes internacionais e de mobilidade de populações.

\section{Referências}

AGAMBEN, G. O que é o contemporâneo? E outros ensaios. Chapecó, SC: Editora ARGOS, 2009. 92p.

ALMEIDA-FILHO, N. Transdisciplinaridade e o paradigma pós-disciplinar na saúde. Saude e Sociedade, v. 14, n. 3, p.30-50, 2005.

APPADURAI, A. Modernity at Large: cultural dimensions of globalization. Minneapolis: University of Minnesota Press, 1996.

ARUNACHALAM, N.; TANA, S.; ESPINO, F.; et. al. M. Eco-bio-social determinants of dengue vector breeding: a multicountry study in urban and periurban Asia. Bull World Health Organ. v.88, n.3, p.173-84, 2010.

BARRETO, M; TEIXEIRA, M.G. Dengue fever: a call for local, national, and international action. Lancet, v. 372, n. 9634, p.205, 2008.

BAUMAN, Z. Amor líquido: sobre a fragilidade dos laços humanos. Rio de Janeiro: Jorge Zahar Ed., 2004.

BIBEAU, G. Quel humanisme pour notre âge bio-tecnnologique? Anthropologie et santé [on line], 1 | 2010. Acesso em 28 de agosto de 2011. Disponível em: http://anthropologiesante. revues.org/91. 
BRODWIN, P. Introduction. In: BRODWIN, P. (Orgs.) Biotechnology and Culture: Bodies, Anxieties, Ethics. Bloomington: University of Indiana Press, 2000, p.1-26.

CAPRARA, A.; LIMA, J.W.; MARINHO, A.C.P.; et al. Irregular water supply, household usage and dengue: a bio-social study in the Brazilian Northeast. Cad. Saúde Pública, v.25, n. 1, p.125-136, 2009.

DESCOLA, P.; PALSSON, G. Nature and society, anthropological perspectives. London: Routledge, 1996.

FASSIN, D. Compassion and Repression: The Moral Economy of Immigration Policies in France. In: INDA, J. X. \& ROSALDO, R. (Org.). The Anthropology of Globalization: a reader. Malden: Blackwell Publishing, 2007. p.212-34.

FASSIN, D. La globalisation et la santé. Éléments pour une analyse anthropologique. In : HOURS, B. (Org.) Systèmes et politiques de santé. De la santé publique à l'anthropologie. Paris: Les Éditions Karthala, 2001. p. 24-40.

FEYERABEND, P. Contra o método. São Paulo : Editora Unesp, 2007.

FISCHER, M., Futuros Antropológicos. Redefinindo a cultura na era tecnológica. Rio de Janeiro: Zahar, 2011. 294p.

FOUCAULT, M. Cours au Collège de France 1978-1979: Naissance de la biopolitique. Paris: Seuil, 2004.

GARGANI, A. (ed.). Crisi della ragione. Nuovi modelli nel rapporto tra sapere e attività umane. Torino: Einaudi, 1979.

GOOD, B.; FISCHER, M.; WILLEN, S.; DELVECCHIO GOOD, M.J. Introduction. In: GOOD, B.; FISCHER, M.; WILLEN, S.; DELVECCHIO GOOD, M.J. (Orgs.) A Reader in Medical Anthropology: Theoretical Trajectories, Emergent Realities. Malden: Wiley Blackwell, 2010. p.1-6.

GOOD, B. Medicine, Rationality and Experience. An Anthropological Perspective. Cambridge: Cambridge University Press, 1994. 242 p.

GUEDES, C.; DINIZ, D. A ética na história do aconselhamento genético: um desafio à educação médica. Rev. bras. educ. med., vol.33, n.2, p.247-252, 2009.

KUHN T. A estrutura das revoluçôes cientificas. São Paulo: Perspectiva, 1989.

LATOUR, B. \& WOOLGAN, S. 1979. Laboratory Life. The Oral Construction of Scientific Facts. Beverly Hills: Sage Publications.

LE BRETON, D. Adeus a corpo. São Paulo: Editora Papirus, 2003. 240p.

LOCK, M.; NGUYEN, V. An Anthropology of Biomedicine. Malden: Wiley-Blackwell, 2010. 506p.

LOCK, M. Medical Anthropology: Intimations for the Future. In: Saillant F \& Genest S. (Eds.) Medical Anthropology. Regional Perspectives and Shared Concerns. Victoria: Blackwell Publishing Ltd, 2007. pp.267-288. 
MARCUS, G; FISCHER, M. Anthropology as cultural critique. An experimental moment in human sciences. Chicago: University of Chicago Press, 1999.

MARCUS, G. Ethnography in/of the world system: the emergence of multi-sited ethnography. Annual Review of Anthropology, vol. 24, p.95-117, 1995.

MARMOT, M. Achieving health equity: from root causes to fair. Lancet, v.370, n.29, p. 1153-1163, 2007.

MASSE, R. Les noveaux défis pour l'anthropologie de la santé. Anthropologie et santé [on line], 1 | 2010. Acesso em 28 de agosto 2011. Disponível em: http://anthropologiesante. revues.org/116.

MORIN E. Educação e complexidade: os sete saberes e outros ensaios. São Paulo: Cortez, 2002.

NICOLELIS, M. Muito além do nosso Eu. A nova neurociência que une cérebro e máquinas e como ela pode mudar nossas vidas. São Paulo: Companhia das Letras, 2011. 534p.

O ESTADO DE SÃO PAULO. Genes podem ser patenteados, decide Justiça dos EUA, 2011. Acesso em 23 de outubro 2011. Disponível em: http://www.estadao.com.br/noticias/ impresso,genes-podem-ser-patenteados-decide-justica-dos-eua,752529,0.htm

ORTEGA, F., ZORZANELLI, R. Corpo em evidência. A ciência e a redefinição do humano. Rio de Janeiro: Civilização Brasileira, 2010.

PARKER R. Administering the Epidemic: HIV(AIDS Policy, Models of Development, and International Health. In: L. M. WHITEFORD \& L. MANDERSON, Global health policy, local realities: the fallacy of the level playing field. Boulder: Lynne Rienner Publishers, 2000. p. 39-56.

RABINOW P.; MARCUS, G.; FAUBION, J.; TOBIAS, R. Designs for an Anthropology of the Contemporary. Durhan: Duke University Press, 2008. 141p.

RABINOW, P. Artificialidade e iluminismo: da sociobiologia à biosociabilidade. In: Antropologia da Razão. Rio de Janeiro: Relume-Dumará, 1999. p.135-158.

SAILLANT, F. \& GENEST, S. Ancrages locaux, défis globaux. Laval: Les Presses de l'Université Laval, 2005.

SCHEPER-HUGHES N. The global traffic in human organs. Curr Anthropol. v.41, p.192224, 2000.

SFEZ, L. A saúde perfeita. Crítica de uma nova utopia. São Paulo: Editora Loyola, 1996. 407p. VATTIMO, G. La Fine della modernità. Milão: Garzanti, 1985.

VAN DONGEN, E.; FAINZANG, S. Medical Anthropology at Home, Anthropology and Medicine, v.5, n.3, p.245-250, 1998.

WHITEFORD, L.M.; MANDERSON, L. Global health policy, local realities: the fallacy of the level playing field. Boulder: Lynne Rienner Publishers, 2000. 


\section{New objects and new challenges for medical anthropology nowadays}

This paper aims to reflect on the emerging objects and theoretical, methodological and ethical challenges in contemporary medical anthropology, addressing two issues in particular: the challenged placed by advances in molecular biology, bio-technologies and predictive medicine, and the analysis of health and illness in the context of globalization. Medical anthropology seems to expand in the coming years in thematic networks around these two major centers: on the one hand, the new definitions of disease and health associated with advances in life sciences and how the human body is built, transformed and redefined as the locus of management of risk and uncertainty; on the other, an increasingly complex, globalized and unequal context we are living in make a more global anthropological approach also necessary, in which the health-disease process should be increasingly analyzed within a complex set of economic policies, international relations and mobility of populations through new approaches to interdisciplinary research nature.

Key words: medical anthropology, globalization, biotechnologies. 